\title{
Comparison of intravenous iron sucrose with oral iron in pregnant women with iron deficiency anaemia
}

\author{
Samar Rudra*, Archana Chandna, Jayati Nath
}

Department of Obstetrics and Gynaecology, MMIMSR, Mullana, Ambala, India

Received: 06 January 2016

Accepted: 08 February 2016

\section{*Correspondence:}

Dr. Samar Rudra,

E-mail: rudra_samar@yahoo.co.in

Copyright: $\odot$ the author(s), publisher and licensee Medip Academy. This is an open-access article distributed under the terms of the Creative Commons Attribution Non-Commercial License, which permits unrestricted non-commercial use, distribution, and reproduction in any medium, provided the original work is properly cited.

\begin{abstract}
Background: The aim of this study was to compare the efficacy and safety of intravenous iron sucrose with oral iron in the treatment of iron deficiency anaemia in pregnancy.

Methods: 200 pregnant women with gestational age between 24 to 34 weeks with $\mathrm{Hb} 7.0-9.0 \mathrm{~g} / \mathrm{dL}$ and peripheral smear features suggestive of iron deficiency anaemia were included in the study and they were randomized in two groups of 100 each. Group A: IV iron group was given $200 \mathrm{mg}$ of Iron sucrose complex in $200 \mathrm{ml}$ of normal saline IV drip, 3 days a week till her calculated required dose has been infused. Group B: oral iron group received ferrous ascorbate oral tablets equivalent to $100 \mathrm{mg}$ elemental iron twice a day during her pregnancy. Various laboratory parameters like hemoglobin, reticulocyte count, $\mathrm{PCV}, \mathrm{MCV}, \mathrm{MCH}, \mathrm{MCHC}$ as well as serum ferritin were measured at recruitment and at 1 week, 2 weeks, 4 weeks of starting treatment, at delivery and at 3 months postpartum. Haemoglobin and ferritin level of cord blood was also measured. Any adverse effects of drug were noted in both the groups. All the relevant data were tabulated and statistical analysis was done.

Results: The change in all the assessed parameters including haemoglobin and ferritin levels from baseline was significantly higher in the intravenous group than the oral group at each point of measurement. IV iron group did not have any serious adverse drug reactions and oral group experienced adverse effects mainly gastrointestinal symptoms. Conclusions: Intravenous iron sucrose treated iron deficiency anaemia of pregnancy faster, and more effectively than oral iron therapy, with no serious adverse drug reactions.
\end{abstract}

Keywords: Iron sucrose, Haemoglobin, Anaemia

\section{INTRODUCTION}

Iron deficiency anaemia (IDA) is a major public health problem all over the world. Pregnant women are the most vulnerable due to its effect on maternal and neonatal morbidity and mortality. Prevalence of IDA in pregnancy is estimated to be $35-75 \%$ (average 56\%) in nonindustrialized countries and $18 \%$ in industrialized countries according to WHO report. ${ }^{1}$ It is responsible for $40-60 \%$ maternal death in non-industrialized countries directly or indirectly. ${ }^{(2,3)}$ In India the prevalence of IDA in pregnancy has been reported to be $57.9 \%$ (54.6\% urban and 59\% in rural) by National Family Health Survey-3 (NFHS) with a wide variation of incidence from state to state. ${ }^{4}$

According to WHO data presented at Federation of International Obstetrics and Gynaecology (FIGO) meeting in 2003 in Chile around 500,000 maternal deaths and 20,000,000 maternal morbidity cases per year are related to iron deficiency anaemia. FOGSI - WHO study on maternal morbidity revealed $64.4 \%$ of women who died, had hemoglobin less than $8 \mathrm{gm} \%$ and $21.6 \%$ had hemoglobin $5 \mathrm{gm} \%{ }^{2}$ 
Various health strategies adopted by Government of India like intake of iron folic acid tablets at least for 100 days during pregnancy and other antenatal interventions has not produced desired results as revealed from NFHS3(2005- 2006) report when compared to NFHS-2(19981999) report. K N Agarwal et al in 2006 in their study of anaemia in Indian rural women found no change in severity of anaemia in last 15 years. ${ }^{5}$

Although oral iron is the ideal therapy for iron deficiency anaemia in pregnancy but various shortcomings like impaired iron absorption, failure to deliver iron tablets to all women during $2^{\text {nd }}$ and $3^{\text {rd }}$ trimester of pregnancy as recommended by ACOG and poor compliance of patient are the major factors for the ineffectiveness of our health strategy. ${ }^{6}$ It takes weeks for oral iron to raise haemoglobin and months to replenish the iron stores in the body. Therefore many women fail to comply with such prolonged therapy.

Though as alternative, parental iron preparations are available and it offers an opportunity to overcome the compliance of patient by administering the total required dose in a short time and at the same time replenishing the iron store, but conventionally parenteral iron therapy is reserved only for a small number of patients in whom oral iron fails due to side effects, iron intolerance, decreased absorption or due to resistance to oral iron. Reason for hesitation to use parental iron by clinician in the past has been various adverse effects of parenteral iron and some of them were serious and even at times fatal. Presently many safe parenteral iron preparations are available in the market. Iron sucrose complex (ISC) is an intravenous preparation widely being used all over the world due to its safety and convenience. There is no reported serious adverse reaction so far. Hence ISC has become an attractive alternative to oral iron in many centers especially for moderate to severe anemia. However many aspects still require to be studied and many to be re-endorsed before we start using ISC as a routine in management of iron deficiency anemia.

This study was undertaken to evaluate the efficacy, safety and acceptability of intravenous iron sucrose complex in comparison to oral iron therapy.

\section{METHODS}

This study was carried out at a rural medical college in Haryana (India) in the Department of Obstetrics and Gynaecology from September 2013 to August 2015. 200 pregnant women with gestational age between 24 to 34 weeks with established iron deficiency anemia, confirmed with $\mathrm{Hb}$ 7.0-9.0 $\mathrm{g} / \mathrm{dL}$ and peripheral smear features suggestive of iron deficiency anaemia were included in the study. Women with any chronic infection, chronic lung, liver, renal or cardiac diseases were excluded from the study.
This study was approved by the institutional ethical committee. The women were recruited for the study after obtaining informed consent. Detailed history, general physical, systemic and obstetric examination findings were recorded on a preformed proforma. Baseline laboratory investigations like haemoglobin, PCV, MCV, $\mathrm{MCH}, \mathrm{MCHC}$, peripheral smear, serum ferritin, urine routine and culture sensitivity, stool for ova/ cyst were carried out prior to enrollment.

Patients fulfilling the criteria were randomized into two groups using computer generated random number table viz. GROUP A: IV iron group and GROUP B: Oral iron group. IV iron group cases were admitted in daycare unit of the department. Intravenous iron sucrose $200 \mathrm{mg}$ in $200 \mathrm{ml}$ of normal saline given by IV infusion ( first dose, initial $12.5 \mathrm{ml}$ was infused over 15 minutes i.e. $50 \mathrm{ml}$ per hour) over a period of 2 hours on alternate days for 3 days a week up to a maximum of $600 \mathrm{mg} / \mathrm{week}$ was administered. The following formula was used: Body weight in $\mathrm{kg} \mathrm{x}$ (target $\mathrm{Hb}$ - initial $\mathrm{Hb}$ ) gm/dl x 2.4 plus $500 \mathrm{mg}$ to calculate the total iron requirement of the patient to fulfil the deficit as well as to replenish the iron stores to make it to $11 \mathrm{~g} / \mathrm{dL}$. Since the pre pregnant body weight was not known, weight on first visit was taken. GROUP B: oral iron group received ferrous ascorbate oral tablets, each containing $100 \mathrm{mg}$ elemental iron twice daily during pregnancy as per the recommendation of World Health Organization for the treatment of iron deficiency anaemia. The target haemoglobin was 11 $\mathrm{g} / \mathrm{dL}$. All the subjects received folic acid tablet once daily. After completion of treatment they were put on one tablet of prophylactic iron folic acid daily till 6 weeks postpartum.

Follow-up evaluation of haematological parameters was done as follows. Haemoglobin and reticulocyte count on day 7; haemoglobin, PCV, MCV, MCH, MCHC on day 14 and 28; Peripheral smear study and serum ferritin were repeated on day 28 after baseline study. At delivery haemoglobin, PCV, MCV, MCH, MCHC, serum ferritin of mother and haemoglobin and serum Ferritin of cord blood of new born were measured. At 3 months postpartum, haemoglobin and serum ferritin of mother were repeated. Clinical improvement in symptoms was also assessed. Gastro-intestinal side effects (nausea, vomiting, constipation, and diarrhoea), pruritus, fever, myalgia, hypotension, local extravasation, thrombophlebitis, metallic taste, anaphylactic reactions etc were noted.

Statistical analysis was done applying student ' $t$ ' test and Chi square test. Value of $<0.05$ was taken as significant and $<0.001$ as highly significant.

\section{RESULTS}

100 cases from each group those who completed the treatment were included in the study. All the pregnant women in IV iron group completed the full calculated 
required dose of iron. Checking of used foils in oral iron group revealed $89 \%$ (89 women) consumed $95 \%$ tablet of iron folic acid issued to them. The remaining 11 women could complete the treatment in a reduced dose.

The two groups were similar in demographic and clinical characteristics as shown in Table 1. All haematological indices measured at each point of time are shown in Table 2.

The baseline laboratory parameters at recruitment were similar in both the groups. Mean value of Hemoglobin was $7.81 \pm 0.44$ and $7.88 \pm 0.45$ in group A and B respectively ( $\mathrm{p}$ value $=0.43$ ). Various other laboratory parameters like reticulocyte count, $\mathrm{PCV}, \mathrm{MCV}, \mathrm{MCH}$, MCHC and serum ferritin also had similar values in both the groups with no statistically significant difference. Rise in all hematological parameters were observed in both the groups following iron therapy at 2 weeks, 4 weeks and at delivery as well as at 3 months post-partum. However the rise in hemoglobin as well as other hematological indices was more in IV iron group than in oral iron group at each point of measurement with statistically significant difference.

Table 1: Demographic \& clinical characteristics.

\begin{tabular}{|llll|}
\hline Characteristics & $\begin{array}{l}\text { IV groups } \\
(\mathrm{A})(\mathrm{N}=100)\end{array}$ & $\begin{array}{l}\text { Oral } \\
\text { groups (B) } \\
(\mathrm{N}=100)\end{array}$ & $\begin{array}{l}\text { P } \\
\text { value }\end{array}$ \\
\hline $\begin{array}{l}\text { Age ( Mean } \pm \\
\text { SD) (yrs) }\end{array}$ & $25.08 \pm 3.32$ & $\begin{array}{l}25.12 \pm \\
3.73\end{array}$ & 0.936 \\
\hline $\begin{array}{l}\text { Low } \\
\text { Socioeconomic } \\
\text { Group }\end{array}$ & $72 \%$ & $76 \%$ & 0.628 \\
\hline $\begin{array}{l}\text { Education upto } \\
\text { primary or } \\
\text { below }\end{array}$ & $70 \%$ & $76 \%$ & 0.425 \\
\hline $\begin{array}{l}\text { Multigravida } \\
\left.\text { BMI (Kg/m }{ }^{2}\right)\end{array}$ & $22.18 \pm 2.42$ & $22.13 \pm 2.37$ & 0.8828 \\
\hline POG (weeks) & $27.61 \pm 2.43$ & $27.76 \pm 2.31$ & 0.655 \\
\hline
\end{tabular}

Table 2: Haematological parameters.

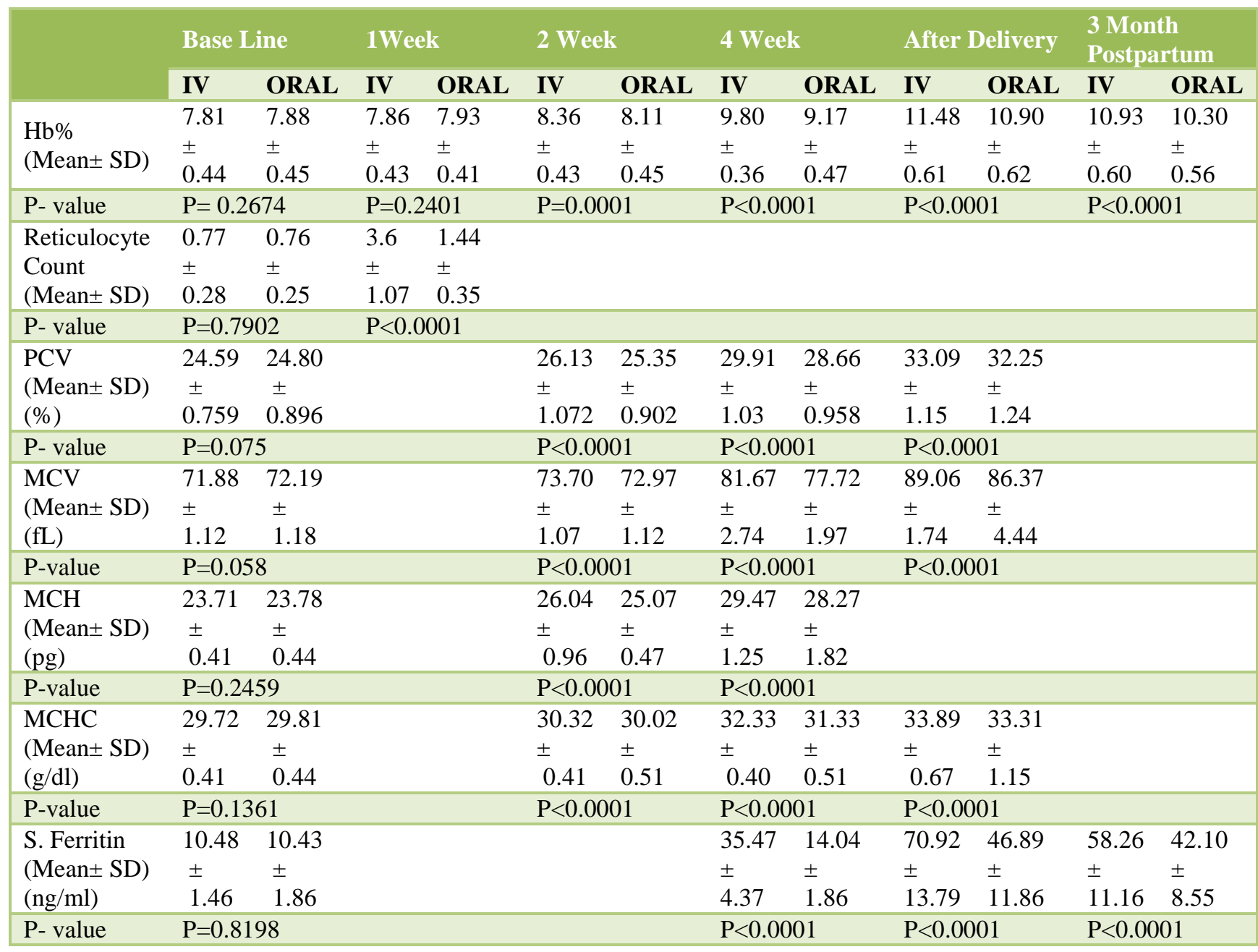


Reticulocyte count at the end of one week from start of therapy was $3.6 \pm 1.07$ and $1.44 \pm 0.35(\mathrm{p}<0.001)$ in IV and oral group respectively indicating a faster response to IV iron therapy. Though the haemoglobin level at one week was $7.86 \pm 0.43$ and $7.93 \pm 0.41 \quad(\mathrm{p}=0.41)$ respectively indicating no significant rise at the end of first week of therapy. However haemoglobin level started rising steadily from $2^{\text {nd }}$ week onwards in both the groups with the increasing trend continuing till delivery. The haemoglobin level at 2 weeks was $8.36 \pm 0.43$ vs. $8.11 \pm$ $0.45(\mathrm{p}=0.005)$; at 4 weeks $9.80 \pm 0.36$ vs. $9.17 \pm 0.47$ $(\mathrm{p}<0.001)$; at delivery $11.48 \pm 0.61$ vs. $10.90 \pm 0.62$ $(\mathrm{p}<0.001)$ and at 3 months postpartum $10.93 \pm 0.60$ vs. $10.30 \pm 0.569(\mathrm{p}<0.001)$ in Group A and B respectively showing significantly greater increase in IV group at each point of measurement. Similarly all other laboratory parameters measured, showed a greater rise in group A at each point of evaluation. Similarly serum ferritin which is considered a surrogate marker of iron deficiency was increased significantly in group A compared to group B.

Table 3 shows amount of rise in haemoglobin from baseline. At 2 weeks, $0.552 \pm 0.13$ and $0.222 \pm 0.16$ $(\mathrm{p}<0.001)$; at 4 weeks $1.99 \pm 0.18$ and $1.27 \pm 0.30$ $(\mathrm{p}<0.001)$ and at delivery $3.67 \pm 0.17$ and $3.02 \pm 0.17$ $(\mathrm{p}<0.001)$ in Group A and B respectively. The rise in haemoglobin in Group A was statistically highly significant at each point of measurement.

Table 3: Rise of haemoglobin from baseline.

\begin{tabular}{|llll|}
\hline $\begin{array}{l}\text { Rise in } \\
\text { Hb\% }\end{array}$ & IV & Oral & P value \\
\hline 2 Weeks & $0.552 \pm 0.13$ & $0.222 \pm 0.16$ & $\mathrm{P}<0.0001$ \\
\hline 4 Weeks & $1.99 \pm 0.18$ & $1.27 \pm 0.30$ & $\mathrm{P}<0.0001$ \\
\hline At delivery & $3.67 \pm 0.17$ & $3.02 \pm 0.17$ & $\mathrm{P}<0.0001$ \\
\hline
\end{tabular}

Table 4 shows various neonatal parameters at birth. Gestational age at birth $38.14 \pm 1.67$ and $38.22 \pm 1.59$ weeks ( $\mathrm{p}=0.931)$, birth weight $2784 \pm 428.4$ and $2684 \pm$ 361.6gms ( $\mathrm{p}=0.076)$, cord blood haemoglobin $15.6 \pm 0.9$ and $15.8 \pm 0.9 \%(\mathrm{p}=0.269)$, cord blood serum ferritin $158.4 \pm 40.2$ and $155.72 \pm 41.94 \mathrm{ng} / \mathrm{ml}(\mathrm{p}=0.745)$ in group $\mathrm{A}$ and $\mathrm{B}$ respectively showing no significant difference.

Table 4: New born parameters.

\begin{tabular}{|lllll|}
\hline & $\begin{array}{l}\text { Gestational } \\
\text { age at Birth } \\
\text { (Mean } \pm \text { SD) } \\
\text { (weeks) }\end{array}$ & $\begin{array}{l}\text { Birth } \\
\text { Weight } \\
\text { (gms) }\end{array}$ & Hb\% & $\begin{array}{l}\text { S. } \\
\text { Ferritin } \\
(\text { ng/ml) }\end{array}$ \\
\hline IV & $38.24 \pm 1.67$ & $\begin{array}{l}2784 \pm \\
428.4\end{array}$ & $\begin{array}{l}15.6 \pm \\
0.9\end{array}$ & $\begin{array}{l}158.4 \pm \\
40.20\end{array}$ \\
\hline Oral & $38.22 \pm 1.59$ & $\begin{array}{l}2684 \pm \\
361.6\end{array}$ & $\begin{array}{l}15.8 \pm \\
0.9\end{array}$ & $\begin{array}{l}155.72 \pm \\
41.94\end{array}$ \\
\hline $\begin{array}{l}\text { P } \\
\text { value }\end{array}$ & 0.9310 & 0.076 & 0.117 & 0.645 \\
\hline
\end{tabular}

There were no serious adverse drug reactions like anaphylactic or hypotensive shock. There were no patient withdrawal and no drug discontinuation caused by drug related adverse events in the intravenous group. Minor adverse events in the intravenous group were fever (two), itching all over the body (one), injection site swelling, redness or pain (four), arthralgia (one) and nausea (four).

In the oral group gastrointestinal symptoms were experienced by 22 women. They include nausea vomiting (four), epigastric discomfort and bloating (sixteen), Diarrhoea (four), metallic test (four) and many of them had combination of these symptoms which were managed by symptomatic treatment. No women discontinued the drug because of gastrointestinal symptoms.

\section{DISCUSSION}

The safety and effectiveness of iron sucrose has been demonstrated in several clinical trials of patients with chronic kidney disease with refractory anemia. ${ }^{7}$ In anaemic pregnant women, Govan and Scott reported a case series as early as in 1949 demonstrating the benefits of intravenous iron. ${ }^{8}$ Subsequently, small observational studies, quasi-experimental studies, and small randomized clinical trials have shown improvement in haematological indices with intravenous iron sucrose in pregnant women.

Iron sucrose is a type II Fe complex that releases iron to endogenous iron binding protein with half-life of 6 hours, are not only effective but carry a minimum risk of allergic accident or overload. ${ }^{9,10}$ Sucrose iron is directly delivered to the haemopoeitic system. It is more bioavailable than other preparations. ${ }^{11}$ Unlubilgin et al conducted a randomized open label study with the aim to compare the efficacy of intravenous iron to oral iron in treatment of anaemia in pregnancy. ${ }^{12}$ They concluded that intravenous iron, treated iron deficiency anaemia of pregnancy and restored iron stores faster and more effectively than oral iron, with no serious adverse reactions.

Our study was conducted in a rural medical college where the prevalence of anaemia is $89 \%$. Mean age of recruitment, socioeconomic and educational status were similar in IV iron (Group A) and oral iron group (Group B) in our study. Average gestational age was 27 to 28 weeks in our study. Analysis of response to therapy shows faster and more increase in the level of haemoglobin in IV iron group than the oral iron group at 2 weeks, 4 weeks, at delivery and at 3 months postpartum which is similar to other studies. ${ }^{13-16}$ Haematological parameters like reticulocyte count, $\mathrm{PCV}, \mathrm{MCH}, \mathrm{MCV}$, $\mathrm{MCHC}$ also had faster rise and higher values in IV iron group in comparison to oral group. Reticulocyte count at the end of one week was significantly higher in IV iron group indicating a quicker response of haemopoietic system to intravenous iron. Ferritin, which is a marker of iron status, was also increased significantly in IV group 
which was similar to other studies. ${ }^{14,16,17}$ Faster increase in haemoglobin level gives a scope to treat a pregnant woman even at 34 to 36 weeks of pregnancy to raise her haemoglobin to a near optimal level by the time of delivery.

Neonatal parameters like haemoglobin and ferritin level of cord blood did not show any significant difference in the two groups indicating no difference to the foetus irrespective of the route of iron therapy to the mother. Similarly our study also shows no significant difference in gestational age at birth and birth weight of the new born in the two groups. But Bayoumeu F et al in their study found increase birth weight in IV iron arm. ${ }^{14} \mathrm{~A}$ study published by Khalafallah et al also did not find any difference in birth weight in IV iron arm vs. ${ }^{18}$ oral iron arm. However they used iron polymaltose instead of iron sucrose. There were no significant adverse effects of the drug in IV iron group. In the oral group a few adverse effects mainly gastrointestinal symptoms were observed.

Main disadvantage of IV iron sucrose is that it requires frequent visit to the hospital by a pregnant woman to receive the complete dose of the drug. It also puts a heavy burden on the hospital. There has been a recent interest in the use of ferric carboxymaltose which can be given in a single dose and it promises to be more effective, well tolerated and has a comparable safety profile to iron sucrose reducing the need for repeated injections and increases the patients comfort and thus compliance. ${ }^{18}$ Further research is required to study its effect in the Indian subcontinent.

\section{CONCLUSIONS}

From our study, we can conclude that Intravenous iron sucrose is a safe and more effective alternative to oral iron therapy for the treatment of iron deficiency anaemia in pregnancy. It also improves haemoglobin level faster than oral iron. However it requires a hospital set up for the delivery of the drug to the patient. Thus it can be a very attractive alternate treatment modality for addressing Iron deficiency anaemia in pregnant women.

\section{Funding: No funding sources}

Conflict of interest: None declared

Ethical approval: The study was approved by the Institutional Ethics Committee

\section{REFERENCES}

1. WHO global database on child growth and malnutrition, Geneva: WHO programme on nutrition. 1997.

2. Bhatt RV. Maternal mortality in India, FOGSIWHO study. J Obstet Gynecol India. 1997;47:20714.

3. Viteri FE. The consequences of iron deficiency and anaemia in pregnancy. Adv Exp Med Biol. 1994;352:127-39.
4. National Family Health Survey (NFHS-3), Ministry of health and family welfare (Government of India). 2005-2006.

5. Agarwal KN, Agarwal DK, Sharma A, Sharma K, Prasad K, Kalitaetal MC. Prevalence of anaemia in pregnant \& lactating women in India.Indian $\mathrm{J}$ Med Res. 2006;124:173-84.

6. American College of Obstetricians and Gynecologists: Nutrition during pregnancy, Washington. ACOG. 1993:1-7.

7. NKF-K/DOQI Clinical Practice Guidelines for Anemia of Chronic Kidney Disease: Update 2000. Am J Kidney Dis. 2001;37:S182-S238.

8. Govan AD, Scott JM. Intravenous iron in the treatment of anemia of pregnancy. Eur $\mathrm{J}$ Obstet Gynecol Reprod Biol. 2005;123(2):S33-S35.

9. Dalal M, Ranjan R, Seth S. Comparison of Oral and Intravenous Iron for Treatment of Iron Deficiency Anaemia in Pregnancy. Indian Medical Gazette. 2002:372-5.

10. Perewusnyk G, Huch R, Huch A, Breymann C. Parenteral iron therapy in obstetrics: 8 Years experience with iron-sucrose complex. $\mathrm{Br} \mathrm{J}$ Nutrition. 2002;88:3-10.

11. Yee J, Besarab A. Iron sucrose: The oldest iron therapy becomes new. Am J Kid Dis. 2002;40:111121.

12. Unlubilgin E, Kandemir O, Yalvac S. Intravenous versus oral iron for treatment of anaemia in pregnancy: a randomized trial. Obstet Gynaecol. 2005;106:1335-40.

13. Momen AK, Meshari A, Nuaim L. Intravenous iron sucrose complex in the treatment of iron deficiency anemia during pregnancy. Eur J Obstet Gynecol Reprod Biol. 1996;69:121-4.

14. Bayoumeu F, Subiran-Buisset C, Baka NE, Legagneur H, Monnier-Barbarino P, Laxenaire MC. Iron therapy in iron deficiency anemia in pregnancy: Intravenous route Versus oral route. Am J Obstet Gynecol. 2002;186:518-22.

15. Abhilasini GD, Sangili H, Rani R. Intravenous iron sucrose and oral iron for the treatment of iron deficiency anaemia in pregnancy: Journal of Clinical and Diagnostic Research. 2014;8(5):4-7.

16. DeebaShafi, Purandare SV, Sathe AV. Iron deficiency anaemia in pregnancy: Intavenous vs. oral route. J of Obstet Gynaecol India. 2012;62(3):31721.

17. Ragip A, Unlubilgin E, Kandemir O, Yalvac S, Cakir L, Haberal A. Intravenous versus Oral iron treatment of anaemia in pregnancy: a randomized trial. Obstet Gynaecol. 2005;106:1335-40.

18. Khalafallah A, Dennis A, Bates J. A prospective randomized, controlled trial of intravenous versus oral iron for moderate iron deficiency anaemia of pregnancy. Journal of Internal Medicine. 2010;268(3):286-95.

Cite this article as: Rudra S, Chandna A, Nath J. Comparison of intravenous iron sucrose with oral iron in pregnant women with iron deficiency anaemia. Int J Reprod Contracept Obstet Gynecol 2016;5:747-51. 